\title{
La apropiación y el uso del espacio público urbano. Los comunes en el parque urbano
}

\section{Appropriation types and use of the urban public space. The commons in the urban park}

\author{
Gloria Jovita Guadarrama Sánchez* \\ Pamela Monserrat Pichardo Martínez**
}

\begin{abstract}
Public spaces in cities are important for inhabitants' wellbeing and quality of life; these are perceived as social goods for the people who share and use them. This text argues that public spaces are collective goods and social constructions in constant reconfiguration. It analytically shows the forms of appropriation over time and governance agreements into the theoretical framework of commons theory with a qualitative focus applied to The Simon Bolivar Park of Toluca City, Mexico. The analysis contributes to the understanding of the complexity of public spaces, goods, and social relations shared between the actors involved.
\end{abstract}

Keywords: public spaces, commons, women in public space, urban parks, property rights

\section{Resumen}

Los espacios públicos en las ciudades son importantes para la calidad de vida de sus habitantes y son percibidos como bienes sociales. En este texto se argumenta que son bienes de propiedad colectiva y construcciones sociales en constante reconfiguración. Analíticamente se explican las formas de apropiación en el tiempo y los acuerdos para su gobernanza en el marco teórico de los bienes comunes, con un enfoque cualitativo aplicado al caso del Parque "Simón Bolívar" de la ciudad de Toluca, México. El análisis abona a la comprensión de la complejidad del espacio público y las relaciones entre los actores que lo comparten.

Palabras clave: espacios públicos, bienes comunes, mujeres y espacio público, parques urbanos, derechos de propiedad.

** Facultad de Ciencias Políticas y Sociales de la Universidad Autónoma del Estado de México, correo-e: monserrat.pichardo@gmail.com 


\section{Introducción}

La ciudad se conforma por múltiples sistemas que la producen y la reproducen, entre ellos ocupan un lugar importante los espacios públicos (plazas, calles, parques, jardines, centros recreativos, culturales o deportivos, áreas compartidas con función social o cívica), ${ }^{1}$ que más allá de su forma física o su estructura material están constituidos por las interacciones de sus habitantes con su territorialidad así como por las relaciones sociales que en ellos tienen lugar. ${ }^{2}$ Socialmente el espacio público tiene una gran importancia al ser el lugar donde sucede la vida pública y por ser símbolo dentro del territorio. También por su centralidad y multifuncionalidad, porque los grupos sociales se integran y excluyen en él; así como por constituir un ámbito para la generación de ciudadanía, de construcción de identidad y sentido de pertenencia. Los actores sociales se reconocen en el espacio público, se visibilizan y se lo apropian a pesar de las desavenencias que surgen entre los grupos que coexisten en él. Su apropiación dota a estos espacios de sentido social, trasciende el tiempo y el territorio.

El espacio público como objeto de estudio entrańa una profunda exigencia reflexiva; este texto aborda las formas en las que el espacio público es apropiado como un bien común en una dimensión de temporalidad y la reconfiguración de las formas de apropiación determinadas por el uso que las personas hacen de él. Para ese propósito se examina el caso del Parque "Simón Bolívar" en Toluca, Estado de México, con especial atención a las reglas informales que lo convierten en un bien común, los grupos que lo comparten y los derechos de apropiación que ejercen. El análisis se organiza en el marco de la teoría de los bienes comunes de Elinor Ostrom (2011) y de su aplicación al estudio de los espacios públicos. Si bien Ostrom no aplicó sus ideas sobre los bienes de propiedad colectiva y los recursos de uso común a los espacios públicos, el marco de su teoría ha sido extendido a este campo de conocimiento por sociólogos, urbanistas y analistas de políticas públicas, entre ellos: Subirats (2016), Amin (2009), Castro Coma y Martí Costa (2016) y Vergara Vidal (2012).

\footnotetext{
${ }^{1}$ En las ciudades se asumen como espacios públicos las plazas, parques y calles, así como otros elementos llamados de infraestructura abierta, como instalaciones deportivas y de recreación al aire libre, los cuales además de ser transitables públicamente, aportan condiciones para mejorar la calidad de vida en la ciudad (Martínez Valdés et al., 2020). En una visión más amplia, el concepto se extiende a los espacios con funciones de expresión y formación política, cívica o cultural y de respuesta social, al margen del tipo de propiedad. Asimismo, se consideran todas las arenas comunes de la vida social que no son privadas, las cuales no siempre están circunscritas a espacios físicos (De Magalhâes, 2010; Amin, 2009).

${ }^{2}$ La territorialidad es entendida como una dimensión espacial de los actores que incluye los valores que éstos atribuyen a un territorio. En términos de Monnet (2010), "un sistema de valores atribuidos a un territorio".
} 
Metodológicamente la aproximación se estructura como una mirada etnográfica-social sustentada en la observación directa de las formas de apropiación del espacio y de sus usuarios, articulada con entrevistas semiestructuradas para la obtención de la información por sector, grupo y usuario individual. El uso del espacio en su dimensión de temporalidad se establece mediante el trazo de secuencias de ocupación que se integran al trazo de perfiles sociodemográficos de los actores, la caracterización de los bienes y de los derechos de propiedad que son ejercidos. La visión sobre el uso y la comunalización temporal del espacio se complementa con información documental de normas y reglamentos, así como con registros históricos de la adscripción y gestión del espacio seleccionado; el análisis integra factores contextuales asociados a las transformaciones socio-económicas del país.

La exposición se ordena en cuatro apartados: el primero presenta la aproximación a la noción de espacio público y la discusión teórica sobre las posibilidades de considerarlo un bien común. El segundo analiza el caso particular del parque urbano "Simón Bolívar" de la ciudad de Toluca en sus dimensiones de uso temporal, derechos de propiedad y formas de apropiación. El tercero aborda las particularidades del grupo de mujeres que lo usan como espacio para actividades económicas de comercio informal. El cuarto apartado aporta las conclusiones del estudio.

\section{El espacio público y la propuesta de los bienes comunes}

En las últimas décadas se han incrementado las investigaciones que abordan al espacio público como concepto nuclear en distintas áreas del conocimiento. De acuerdo con Lefebvre (2013: 24), se fragmenta en objetos de estudio con sus propios métodos de acuerdo con la ciencia que de él se ocupa.

En este artículo se hace un acercamiento al espacio público bajo la concepción de que es la unión de dos vertientes: la primera se refiere al conjunto de relaciones sociales, simbólicas y de territorialidad que configuran el ámbito legítimo del conflicto político. La segunda corresponde a la visión del espacio público visto en términos físicos, espaciales, tangibles y estructurales:

Esto significa que el espacio público no se agota ni está asociado únicamente a lo físico-espacial (plaza o parque), sea de una unidad (un parque) o de un sistema de espacios (trama urbana). Es, más bien, un ámbito contenedor de la conflictividad social que tiene distintas posiciones, según la coyuntura y la ciudad que se trate (Carrión, 2016: 18). 
Desde ese ángulo integrador, el espacio público es visto como un generador de bienes económicos, recreativos, relacionales, sociales, de pertenencia, susceptibles de ser apropiados. La consideración del mismo como bienes comunes alude al conjunto de recursos naturales, infraestructura, formas de uso, apropiación y control que son compartidos por quienes lo disfrutan y gobiernan.

La visión de Ostrom (2014) sobre los bienes comunes ${ }^{3}$ permite profundizar el análisis de las relaciones sociales que surgen en los espacios públicos de acuerdo con las características de la apropiación que los usuarios hacen de ellos, mediante las nociones de regímenes de propiedad y derechos de propiedad (Ostrom, 2014). Los regimenes de propiedad refieren al tipo de sujeto titular de la propiedad o a quienes son los titulares de los derechos sobre los bienes. Ostrom reconoce cuatro tipos de régimen, a saber: 1) Régimen de acceso abierto: el acceso a los bienes está abierto para cualquier individuo; 2) Régimen de propiedad pública: es el gobierno (federal, estatal, municipal) el dueño de los bienes y puede establecer reglas de uso y cuidado; 3) Régimen de propiedad colectiva: son bienes que se poseen colectivamente; 4) Régimen de propiedad privada individual: el titular es una persona que decide cómo utilizar y proteger los bienes (Merino Pérez, 2019).

Schlager y Ostrom (1992) conceptualizan los derechos de propiedad como sistemas en los que los derechos son acumulables y marcan límites al acceso, uso y decisión que se puede hacer sobre un bien, conformando racimos de derechos. Son las "relaciones sociales alrededor de los bienes y remiten a las capacidades de reclamar el respaldo de un determinado colectivo en la demanda que se hace respecto a un bien" (Merino Pérez, 2014: 91). Pueden estar en manos distintas al titular de la propie$\mathrm{dad}$, es decir, que alguien tenga derecho no lo convierte en el poseedor de la propiedad.

Ostrom (2014: 31) considera seis derechos de propiedad que se encuentran divididos en dos grandes tipos: los derechos de uso, dentro de los cuales están: 1) Acceso: derecho a entrar a una propiedad específica (puede ser sólo durante un periodo determinado);2) Extracción: derecho de extraer productos específicos de un bien; 3) Explotación comercial: derecho de vender. Asimismo, los derechos de control, entre los que considera: 4) Manejo: derecho a transformar el bien y regular patrones internos de uso; 5) Exclusión: derecho a decidir quiénes tienen derechos de

\footnotetext{
${ }^{3}$ Ostrom no aplicó sus ideas sobre los bienes de propiedad colectiva y los recursos de uso común a los espacios públicos, pero el marco de su teoría ha sido extendido a este campo de conocimiento por sociólogos, urbanistas y analistas de políticas públicas.
} 
acceso, uso o manejo del bien; 6) Alienación: el derecho a rentar, vender o hipotecar un bien.

La percepción que los actores sociales tienen de sus derechos (de propiedad) se vincula con los tipos de uso que hacen de cada espacio público. Los diferentes usos de un mismo espacio pueden determinar tipos de bienes distintos, dependiendo el momento en que se apropie y de quién se lo apropie. Para Ostrom (2014) existen cuatro tipos de bienes: bienes públicos, bienes de uso común, bienes tarifa, bienes privados; su clasificación responde a dos condiciones: a) La capacidad de exclusión: posibilidad de excluir a usuarios potenciales del uso de un bien; b) Nivel de sustractabilidad: se refiere a la medida en que el uso actual que realiza un grupo o una persona afecta el uso potencial que lleven a cabo otros usuarios. Si el uso afecta la disponibilidad del bien eso lo vuelve de alta sustractabilidad (Merino Pérez, 2019). En ese sentido, aunque no es el único factor, como lo sostiene Vergara Vidal (2012), es el uso que se hace del espacio lo que determina su carácter.

Así, cuando se habla de momento en este texto se considera que el espacio público cumple distintas funciones (Fonseca Rodríguez, 2015) que se transforman a lo largo del día, la semana, el mes y el año como consecuencia de la interacción social cotidiana y de la diversificación de actividades de los sujetos que coinciden en él. Es decir, se reconfigura a partir del uso que de él se hace y de quién lo hace, en una dimensión de temporalidad. Es el uso, de nueva cuenta, lo que lo convierte en un bien común.

Respecto a los tipos de bienes, Subirats (2016: 78) afirma que debido a las transformaciones que han traído consigo los nuevos funcionamientos de la economía global y neoliberal se ha hecho una reconfiguración de los mismos, pues en un principio los fundamentos de rivalidad y exclusión permitían la clasificación casi perfecta de los bienes en públicos, privados, club y comunes. Sin embargo, ahora hay dos procesos que suceden en paralelo y que modifican esta propuesta. A saber:

Por un lado, el cambio tecnológico ha aumentado la exclusividad en ciertos bienes que eran considerados de exclusividad difícil (pago por acceso a ciertos servicios-bienes, o pago por mejores prestaciones). Por otro lado, la escasez (real o generada) de ciertos bienes que eran considerados no rivales (agua, suelo, tiempo, etc.) han generado una mayor presencia de rivalidad de uso.

Pero, de manera aparentemente contradictoria, la tecnología ha hecho asimismo que ciertos bienes que eran rivales (conocimiento, cultura, arte, etc.), ahora puedan dejar de serlo, al no ser tan importante la propiedad de los mismos (tener físicamente el libro o el cd) como poder acceder a ellos. Lo que parece evidente es que el desarrollo tecnológico y la real o aparente 
escasez de un recurso (mezclando variables como costo marginal de acceso y facilidad de exclusión) pueden modificar y han modificado un escenario antes más estable. Y ello puede situar a los bienes comunes en una nueva centralidad (Subirats, 2016: 78).

En cuanto al espacio público, Subirats se refiere a lo público: a) como aquello que corresponde a lo estatal o $b$ ) como aquello que representa un recurso (o bien) comunitario, y es en el segundo sentido donde hace hincapié en el conjunto de acuerdos que surgen entre actores sociales para gestionarlo y regularlo.

De acuerdo con Subirats (2016: 73), el término bien común surge de dos enfoques distintos. El primero hace referencia al procomún, procomunes o common's (en inglés), que es el tipo de recurso (o bien) que cuenta con la posibilidad de que sea la colectividad que lo usa la que lo gobierne al ser ella la que se beneficia y dispone de él. El segundo refiere a la forma en que el espacio público puede ser concebido como un bien común, el cual no tiene restricciones de acceso y uso colectivo porque se trata de un tipo de propiedad de dominio público ligado al dominio del Estado.

Aquí se considera al espacio público como un bien común con base en el primer enfoque, pero se reconoce que los factores que lo determinan son variables y combinan de manera distinta las interacciones del gobierno con otros actores sociales. Atutxa refiere que el término común debe entenderse más allá de los límites legales o normativos, pues éste únicamente puede ser entendido en la esfera o dimensión en la que se aplica. Lo común "son experiencias que desde la acción transforman la realidad" (Atutxa, 2017: 102).

En el mismo sentido, Giglia (2013: 28) afirma que el espacio público es el bien común más relevante que existe en la ciudad, ya que la participación de los actores sociales en la gestión colectiva comienza desde el momento mismo en que se cruzan los límites de lo privado, por ejemplo, la casa para intervenir en él. Sigue a Ostrom en su idea de que es necesario que exista un acuerdo entre usuarios sobre las reglas que indiquen qué está permitido y qué no en un espacio público determinado; por lo que

en ausencia de reglas compartidas la gestión colectiva del bien comúnespacio público no puede funcionar, y de facto no funciona. No es casual que esas reglas introduzcan cambios notables en los usuarios del lugar y en las formas legítimas de uso, limitando su acceso y su disfrute a ciertos habitantes e impidiéndoselo a otros. Y tampoco es casual que reglas de uso diferentes y contrastantes coexistan de una manera no del todo armoniosa (Giglia, 2013: 29). 
En ese marco, siguiendo a Castro Coma y Martí Costa (2016: 135) se puede decir que el espacio público como bien común debe considerar un grupo de personas unidas por el sentido de pertenencia hacia ese espacio, que mediante un conjunto de reglas compartidas sea capaz de administrar, tomar decisiones y regular ese bien. Subirats (2016) argumenta que si para el caso de algunos lugares de la ciudad se aplica el concepto de bienes comunes, es necesario saber hasta dónde es posible hablar entonces de un espacio común teniendo en consideración que un bien común se encuentra

sometido a la disponibilidad de la comunidad entendida en este caso como comunidad de personas e individuos que, dadas sus interrelaciones y sus lazos de confianza y de reciprocidad deciden ejercer su capacidad de acción en un espacio público [...] (Subirats, 2016: 92).

Las reflexiones vertidas convergen en la necesidad del análisis del impacto de la acción social dentro del espacio público considerado como bien común; así, es indispensable pensar en lo común como una producción social en constante resignificación y como una relación intersubjetiva entre el espacio y los actores (Monnet, 2010); es decir, se concibe que lo común más allá de encontrarse dentro de los márgenes estrictos de lo que es público o es privado, es aquello que tiene origen y sentido sólo dentro de los límites de una comunidad que lo produce colectivamente (Campos Cortés y Brenna Becerril, 2015).

En resumen, las formas de apropiación del espacio público como bien común estarían determinadas por su uso, con la aclaración de que las relaciones que se mueven en su interior son dinámicas, complejas e integran una vasta cantidad de elementos que construyen su significación social. Las relaciones, usos y formas de apropiación se muestran enseguida para el caso de un parque urbano que concentra distintos actores, acuerdos y desacuerdos que sustentan la consideración de verlo como un bien común.

\section{El Parque "Simón Bolívar", un espacio público y bien común}

En el centro de la ciudad de Toluca a un costado del edificio más emblemático de la Universidad Autónoma del Estado de México (UAEM) conocido como Rectoría se encuentra el Parque "Simón Bolívar", rodeado por las calles de Instituto Literario, Ignacio López Rayón y Valentín Gómez Farías, el cual cuenta con una extensión de 4,134 metros cuadrados. Lleva el nombre del libertador venezolano más importante de América del Sur, cuya estatua ecuestre se erige justo en medio del jardín. Fue fundado en 
1930 a petición de una asociación de jóvenes, la Liga Estudiantil contra el Imperialismo Yanqui y en 1996 el Ayuntamiento de Toluca entregó a la Universidad la administración del parque para que se utilizara como jardín de arte para organizar actividades artísticas y culturales, tales como audiciones, talleres, exposiciones y otros (Peñaloza García, 2015: 150).

En la actualidad, el Parque "Simón Bolívar" está destinado para el ocio y el goce, tiene en su interior juegos infantiles, bancas de cemento y bancas metálicas, faroles y árboles. Es utilizado para entrenamientos de parkour y para patinar los fines de semana. Dos de sus esquinas, las que articulan las avenidas Valentín Gómez Farías con Ignacio López Rayón y ésta con Instituto Literario se han convertido en paradas consuetudinarias de autobuses urbanos. En algunas ocasiones se organizan eventos culturales, pero también todos los martes y viernes desde aproximadamente las 10:30 de la mañana y hasta las 16:00 horas se convierte en un punto de venta o centro de intercambio para muchas mujeres que comercian diversos tipos de productos. Muchas de ellas realizan entregas de lo que han vendido con anterioridad por internet a través de Facebook.

Durante las mañanas, entre semana, se observa el movimiento constante por parte de la gente: el tránsito vehicular es fluido y permanente a su alrededor; las personas bajan y transbordan en el transporte público. Llegan los trabajadores de la Universidad. Las bancas son ocupadas y desocupadas y así, conforme pasan los minutos, el parque comienza a cobrar vida, a poblarse, a producirse y ya no se detiene hasta que llega la noche. De esta manera, el espacio del parque va siendo apropiado por distintos actores que hacen uso de él a partir de las actividades que desarrollan.

Muy temprano, las parejas se explayan y hasta se acuestan en las bancas mientras se toman un atole y se muestran afecto. Los padres de familia transitan rápidamente mientras llevan a sus hijos a la escuela. El vendedor de tamales comienza la jornada desde muy temprano. El minúsculo local de lámina del cerrajero, así como la lavandería, la miscelánea y la heladería comienzan a abrir las cortinas, los empleados de los negocios establecidos o sus dueños empiezan sus actividades. La patrulla municipal permanece estacionada en una esquina.

Poco a poco se van intensificando la aparición y la permanencia de las personas en el parque. Por la tarde, algunos de los padres que han ido por sus hijos a la escuela se detienen un rato y permiten que los niños se suban a los juegos que están instalados en el interior del parque. Algunos trabajadores se sientan en las bancas a fumar y a platicar. La gente que va y viene en el transporte público se sienta a esperar durante periodos variados la llegada del autobús que la lleve a su destino (fotografía 1).

Se observa entonces que el parque es apropiado de distintas formas dependiendo del uso que los actores hacen de él, de sus intereses, de su 


\section{Fotografía 1 \\ Aspecto del Parque "Simón Bolívar" de Toluca}

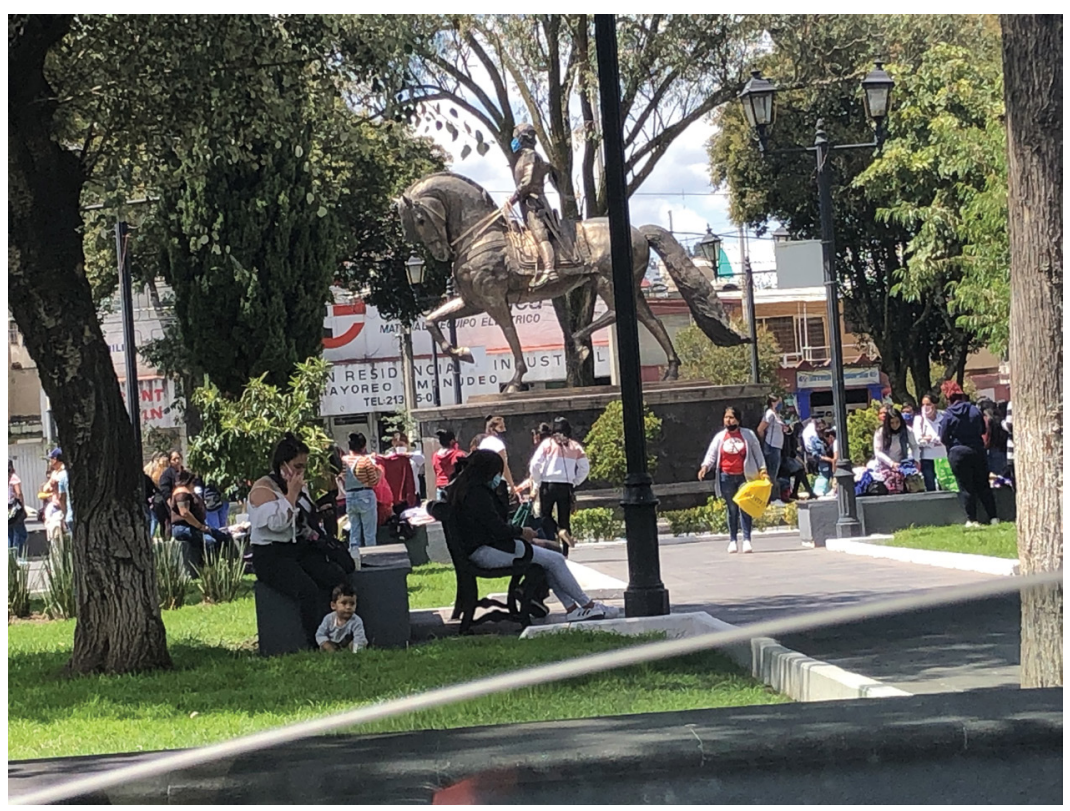

Fuente: autoría propia.

contexto, de sus características, de la hora o el día de la semana. ${ }^{4}$ En las distintas lecturas que se han hecho sobre la apropiación de los espacios públicos y su significación social se observa cómo la forma de apropiación puede transformarlos en bienes de propiedad colectiva. Segovia (2007: 9) afirma que la apropiación de los espacios públicos ayuda a generar sentido de pertenencia por parte de la gente que hace un esfuerzo de integración y de convivencia social en la ciudad. Siguiendo las aportaciones de Almada (2014), se considera que las relaciones sociales establecidas entre las personas dotan al espacio público de una forma determinada, un conjunto de funciones y significaciones sociales. Torres Veytia (2009) advierte que se puede entender la apropiación del espacio público como la creación de un ámbito de pertenencia que comienza con una percepción subjetiva por parte de los actores sociales acerca de su conexión con el territorio.

En la misma línea de la construcción intangible del espacio público están las ideas de otros autores (Vázquez Ceballos et al., 2011), quienes unen lo material, lo económico, el ordenamiento legal e ilegal y la presencia física

\footnotetext{
${ }^{4}$ La secuencia del uso del parque se estableció mediante una técnica de observación directa a lo largo de un ańo de acudir al parque en horarios diferentes (febrero de 2019 a enero 2020) y de la integración de bitácoras de observación.
} 
en el espacio; al tiempo que toman en cuenta lo social, señalan que da lugar al uso compartido de códigos que no implican la presencia física. Sostienen que al hablar de espacios públicos se hace referencia a dos formas de apropiación: material (manifestaciones en la calle que no permiten el adecuado flujo vial) y simbólica (que sirve para compartir códigos de varios tipos entre grupos de personas que ayudan a tener control o dominio sobre el espacio público). Estas formas de apropiación tienen como objetivo la exclusión de otras personas que podrían hacer uso del mismo espacio público, pero con otras características de acción, pues se convierte en un lugar donde existen distintas visiones y proyectos de cada grupo social que hace uso de él.

En la descripción de las interacciones que tienen lugar en el parque es evidente que los usos y las formas de apropiación se reconfiguran al discurrir el tiempo; los tipos de uso abarcan actividades recreativas, económicas y culturales. En principio parece que, por su carácter de espacio público gestionado y controlado por el gobierno municipal y por la Universidad, prevalecieran derechos de acceso para todos en todo momento; pero si se observa con atención se nota que hay usuarios que ejercen otros derechos de uso y de control que van más allá de poder transitar por ese espacio. Por ejemplo, hay quienes acceden al parque sólo con propósitos de ocio y goce, como los niños al término de sus clases, las parejas de novios o quienes practican actividades deportivas. También están quienes acceden, usan y se apropian temporalmente del espacio como las vendedoras ambulantes y las compradoras que anudan las actividades de comercio informal. Están quienes acceden, usan y controlan temporalmente el espacio como pueden ser algunas mujeres que dedicándose al comercio informal rentan los lugares, las bancas, los espacios a las vendedoras para permitirles desarrollar actividades de intercambio económico.

Un punto esencial al pensar al espacio público como bien común son los desencuentros respecto a las reglas de uso y cuidado, porque cuando no hay claridad, se suele desembocar en conflictos y enfrentamientos (Giglia, 2013: 29). El parque cuenta con un conjunto de disposiciones formales emitidas por la autoridad municipal, pero su manejo es un entramado de arreglos informales entre las autoridades y usuarios, que lo mantienen como un espacio en el que es posible establecer vínculos de convivencia y cohesión social, al mismo tiempo que de tensión y exclusión.

Así, aquello que se considera común se produce socialmente todo el tiempo y por lo tanto se resignifica bajo esa dinámica en la que intervienen las prácticas, las actividades y las experiencias que surgen de la constitución y modificación de las relaciones sociales. Por lo tanto, es necesario comprender que un bien común permite analizar las relaciones que se conforman entre personas o grupos de personas, y al mismo tiempo, 
la forma en que éstos se vinculan con los espacios que usan, transitan u ocupan (Campos Cortés y Brenna Becerril, 2015: 160).

Sin trazar líneas divisorias absolutas, no habría que perder de vista que el espacio público es comúnmente parte de la propiedad pública y del dominio del Estado, por lo que su regulación y uso le competen, como figura central en los acuerdos de gobernanza involucrados en la gestión y provisión del espacio. En otras palabras

la conceptualización del espacio público y lo común es propia de una época en que su principal gestor es el Estado, de ahí su prolongada tradición que asocia lo público a lo común y que alude a lo que es de interés o utilidad común a todos los miembros de la comunidad política, lo que atañe al colectivo (Campos Cortés y Brenna Becerril, 2015: 166).

Derivado de ese papel central el Estado asume el carácter de árbitro en los conflictos generados por el uso y la apropiación y busca que los ciudadanos se adhieran a las decisiones. La gobernanza interpretada aquí como modo de gobernar sustentado en arreglos cooperativos o negociados entre actores de distintos sectores sociales para el ordenamiento de la vida pública y como forma de gestión colectiva en torno a objetivos comunes (Porras, 2016), conlleva establecer procesos consensuados y voluntarios sobre los derechos de acceso, uso y control del espacio público.

En las interacciones que presupone la gobernanza resulta evidente que cada espacio público alberga una amplia posibilidad de apropiaciones colectivas y por lo tanto es necesario que sean atendidos y resueltos los requerimientos y demandas de quienes lo usan, para que se privilegien las cuestiones de interés general. La gobernanza implica que el Estado es responsable de que en su uso prevalezca ese interés; no obstante, las organizaciones civiles y los propios ciudadanos son, asimismo, vigilantes y garantes del interés público, y en ese sentido los espacios públicos son además de una infraestructura cívica lugares generadores de ciudadanía.

Son un bien común diseñado para el encuentro y el desencuentro social; por lo que sólo la ciudadanía sensibilizada será quien ejerza el control del espacio como un bien común, con reglas y normas para garantizar su vitalidad, su protección y equidad en el acceso y control (Campos Cortés y Brenna Becerril, 2015: 174).

Se perfila así que el espacio público integra las reglas de uso aceptadas de manera común. Pero también se advierte que el hecho de que sea común no significa que pertenece a todos o que todos tengan permiso para usarlo, se identifica como bien común, porque es de propiedad colectiva y/o comunitaria, también porque la comunidad se integra a su gobierno. 
La naturaleza colectiva y comunitaria de los espacios públicos deja ver que están sujetos a procesos de competitividad por su uso, por lo que se constituyen como bienes escasos que deben ser defendidos y gobernados colectivamente. El involucramiento colectivo y comunitario responde también a que se han observado procesos de disminución de las responsabilidades de los gobiernos en su preservación o mantenimiento y tendencias hacia su privatización.

Si se piensa el espacio público como un bien escaso o en riesgo de pérdida, es imposible concebirlo como un lugar fuera de conflictos de derechos, al momento de decidir quién y cómo se usa, por lo que se vuelve necesaria la existencia de reglas institucionales formales o implícitas por parte del gobierno al que le corresponde su gestión. En el caso del Parque "Simón Bolívar", su gestión y organización en cuanto al uso y cuidado del mismo son responsabilidad del gobierno municipal de la ciudad. ${ }^{5}$

En conclusión, se puede decir que el panorama de los actores y usos del parque en su dimensión de temporalidad revela que se encuentra en constante reconfiguración a lo largo del día, de las semanas y de las estaciones; y que sus usuarios se apropian de sus espacios de manera distinta. Asimismo, se advierte su carácter de propiedad colectiva sujeta a las interacciones y acuerdos de gobernanza que han aceptado sus usuarios y los responsables de su gestión en la ciudad. Se visibiliza en este punto que un solo espacio público se comporta como una multiplicidad de espacios dependiendo de los acuerdos especiales que se establecen entre el gobierno y los grupos de actores diferenciados, esto genera tensiones por la búsqueda de igualdad en los derechos que se les conceden.

\section{Una apropiación particular del espacio público en el Parque "Simón Bolívar": las mujeres y el comercio informal}

Las formas de apropiación de los espacios públicos dependen del contexto y ritmo propio de cada espacio, es decir, de su centralidad, de sus posibilidades para la movilidad, del propósito para el que han sido hechos, de aquellos que lo proveen y lo gestionan, entre otros factores. En el caso del Parque "Simón Bolívar" se detectó una intensa actividad económica desarrollada principalmente por mujeres que han convertido al parque en el centro de operaciones comerciales informales desde hace más de cinco años con un patrón específico de días y horarios en los que se reúnen para realizar intercambios: compras o trueques.

\footnotetext{
${ }^{5}$ Subirats sostiene que "la creciente competencia en los usos de los limitados espacios públicos en las ciudades genera conflictos de derechos y de percepciones sobre la legitimidad de cada actividad y de cada colectivo con relación a un mismo espacio" (2016: 90).
} 
La presencia y el uso que ellas hacen de este espacio urbano se vincula, de modo estrecho, con los procesos de precarización laboral en los que los ingresos son insuficientes para el gasto familiar, con el aumento del desempleo, el incremento de empleos ocasionales y temporales que no otorgan derechos a los trabajadores, la subcontratación que desaparece no sólo los puestos de trabajo sino los beneficios y prestaciones, e incluso con las normas laborales que constrińen a los empleados. En ese contexto, las mujeres se enfrentan a constantes elecciones que implican renuncias totales o parciales, pérdida de tiempo libre o incluso dobles jornadas. Se complican los horarios, las cargas laborales, las exigencias, los traslados frente al cuidado de los hijos, tareas que están determinadas como una función única de las mujeres en muchos lugares. Estos procesos han traído como consecuencia una mayor integración por parte de las mujeres en el mercado laboral no sólo en empleos establecidos o formales, sino que han hallado salidas en actividades que les proveen de ingresos a partir del autoempleo, en este caso, a través de las ventas por catálogo, de mercancías de procedencia diversa, de manualidades, de ropa de segunda mano, de piratería, entre otros rubros, para contribuir, o hacer frente en su totalidad, a los gastos familiares. Así, muchas mujeres han encontrado en el comercio informal las condiciones que les permiten, de una u otra forma, cumplir con las distintas responsabilidades que forman parte de la posición y condición que ocupan en la sociedad.

Frente a esta situación cada vez más generalizada se puede analizar el caso del Parque "Simón Bolívar" en el que los martes y viernes se desarrollan actividades comerciales informales en las que se observan intercambios económicos, prácticas de negociación y establecimiento de acuerdos con el entorno, de mujeres que se apropian del espacio público. Para empezar, se puede pensar que durante los más de cinco años que ellas se han apropiado del parque con intenciones comerciales han establecido acuerdos tácitos de convivencia y respeto tanto entre vendedoras como compradoras, lo que les ha permitido arraigarse en el lugar a pesar de las normas legales que prohíben esta clase de intercambios, pues aunque gran parte del tiempo hay rivalidades, en los momentos álgidos frente a las autoridades actúan como un grupo cohesionado (la mayor parte de las veces). Este comportamiento individual pero solidario cuando se requiere les ha permitido permanecer en el parque.

En términos de los bienes que se combinan en sus actividades, se observa primero que el Parque "Simón Bolívar" tiene un régimen de propiedad pública, pues es el gobierno municipal el que establece las reglas de uso y de su cuidado, aunque la encargada de su administración desde 1996 es la Universidad Autónoma del Estado de México, que no asume responsabilidades de regulación. El Bando Municipal de Toluca (Gaceta 
Municipal Especial, 2019) resulta muy interesante para los ejes de este análisis, pues maneja términos como Bien de dominio público o Bien de uso común. ${ }^{6}$

Ahora bien, en cuanto a los derechos que los ciudadanos en general tienen sobre el parque se encuentra el derecho de acceso, que es el primero entre los derechos de uso y que se expresa como libre tránsito por el espacio en todo momento; pero el uso cambia o se restringe cuando se busca el ocio y la recreación porque los espacios de juego o reposo se ocupan y desocupan en el transcurrir del tiempo; el uso del espacio se restringe o negocia, e incluso se vuelve excluyente, cuando algunos usuarios o autoridades se apropian de los lugares con derechos de control. Si se toma en cuenta el tipo de bien, es ostensible que el parque es un bien público los días lunes, miércoles, jueves, sábado y domingo porque los actores pueden acceder a él sin dificultad y porque no hay problemas de rivalidad, pues no todos sus usuarios se encuentran ahí durante todo el día y por lo tanto no hay alta sustractabilidad que impida que los presentes en un momento determinado gocen del bien de manera igualitaria.

Pero el comportamiento de los actores en el parque, en este caso las mujeres, hacen que éste transite de ser un bien público a un bien común con reglas de uso los días martes y viernes de las 10:30 a las 16:00 horas aproximadamente, pues no es posible que las autoridades impidan el acceso a las mujeres vendedoras, pero ellas tampoco pueden impedírselo a otras, y es aquí donde el nivel de sustractabilidad se eleva debido a que el espacio público se vuelve escaso en la medida en que vendedoras ambulantes y compradoras se apropian de los espacios no sólo en términos económicos sino físicos, lo que vuelve muy difícil la convivencia entre ellas porque esos días, en esos horarios, algunas se sienten literalmente dueñas del piso sobre el que se encuentran. Esto, debido a que de forma consuetudinaria han legitimado frente a compradoras y otras vendedoras, la apropiación del lugar en el que distribuyen su mercancía. Es decir: los días martes y viernes, por ejemplo: la banca que se encuentra del lado de los juegos instalados en el parque 'pertenece' a " $x$ " mujer, lo cual es

\footnotetext{
${ }^{6}$ En su Capítulo Segundo prohíbe el ambulantaje fijo o móvil salvo algunas excepciones que favorecen a los grupos que se consideran vulnerables o con derechos de residencia (Gaceta Municipal Especial, 2019: 47). En el Capítulo Cuarto, De las Infracciones y sanciones, el artículo 104 considera una violación a las normas cuando se invade algún bien de dominio público o de equipamiento urbano para el ejercicio de actividades comerciales. También se considera infracción la utilización de la vía pública para el comercio no permitido por la autoridad municipal (Gaceta Municipal Especial, 2019: 51). El artículo 105 considera dentro de las infracciones graves al comercio ambulante, semifijo y fijo que no cuente con autorización (incluso más que las del ejercicio del trabajo sexual, tener relaciones sexuales en la vía pública, espacios públicos o de uso común que se consideran como no graves). Con esto quedan claras las reglas y normas legales que deben obedecerse en cualquier espacio público del municipio.
} 
reconocido por aquellas con quienes se ha encontrado históricamente en el parque.

Tiene lugar entonces un fenómeno ambivalente: una tensión constante entre las mujeres que venden que puede anunciar un conflicto abierto, pero al mismo tiempo, cuando se ven amenazadas por las autoridades municipales pueden establecer sistemas de cooperación en los que se 'dan el pitazo’ o se ayudan a recoger la mercancía para poder irse; cabe aclarar que estos sistemas de cooperación no siempre están presentes, pues sí hay momentos en que algunas de las vendedoras son 'levantadas' por las autoridades y las demás permanecen incólumes observando esas escenas para no meterse en problemas.

Vale la pena señalar que ni todas las vendedoras ambulantes ni todas las compradoras pertenecen a los mismos estratos sociales, existe una diversidad significativa entre sus motivaciones, sus recursos de movilidad, sus posibilidades de inversión, su edad, la composición de sus hogares y su capital cultural que, en este caso, depende mucho de sus posibilidades de empleo de recursos tecnológicos o medios digitales de comercio y pago. En consecuencia, aunque la apropiación que las mujeres hacen del Parque "Simón Bolívar" es económica, las formas en las que se lo apropian son diferentes. Hay desigualdades evidentes que complejizan las oportunidades de arranque para todas ellas y que son determinantes sobre los productos que venden o compran y la calidad de los mismos, la forma de transportarlos, la manera de realizar la negociación, la forma de pago, la posibilidad de la discreción al momento de concretar la venta o la entrega de la mercancía, los horarios familiares, laborales o escolares, las distintas maneras de vivir sus roles maternos y hasta el estado civil. ${ }^{7}$

Lucía es esa clase de mujer que no aparenta la edad que tiene, su cara luce aniñada y viste como adolescente despreocupada. Tiene 28 ańos, estudió hasta la preparatoria y es casada. Ella se dedica a la venta de ropa de segunda mano porque, aunque afirma que ella provee $50 \%$ de los ingresos familiares, su esposo sólo ha encontrado trabajos temporales. Él es ingeniero y ella mantiene su casa.

Tiene una página en Facebook que actualiza cada semana con la mercancía que vende: publica fotos de cada prenda, talla, color y precio. Tiene un estricto reglamento para negociar la venta porque "las fallas han sido muchas", afirma. Recibe depósitos bancarios o pagos en efectivo a contraentrega en el parque, lugar al que llegó hace cinco años porque una amiga

${ }^{7}$ El perfil del grupo se traza como resultado del conjunto de entrevistas que tuvieron lugar entre julio de 2019 y enero de 2020, cuyos nombres fueron cambiados para proteger la privacidad de las entrevistadas. Las entrevistas a profundidad semiestructuradas realizadas a vendedoras ambulantes del Parque "Simón Bolívar" en la ciudad de Toluca, Estado de México, de julio de 2019 a enero de 2020, fueron llevadas a cabo por Pamela Monserrat Pichardo Martínez. 
suya la integró a varias de las redes de mujeres que se han consolidado en grupos de Facebook. Se puede decir que es una veterana en el lugar y lo ha visto cambiar a través del tiempo.

$\mathrm{Al}$ principio eran muy poquitas personas. Me acuerdo que eran como cinco personas las que entregaban ahí y poco a poco empezó a crecer... Empezaron a llegar más y más chavas a vender y a comprar. Recuerdo que había una señora que comenzó vendiendo, La Morena, que después dejó de vender y nos rentaba los espacios a 30 pesos a la semana ${ }^{8}$ y a cambio nos daba una credencial y todas debíamos tenerla para tener derecho de vender, según ella (Lucía, entrevista personal, 2019a).

Ana María tiene 43 años, estudió hasta la preparatoria y recuerda las dificultades que enfrentó al comenzar a vender ropa de 'paca' en el parque por el trato con las otras mujeres vendedoras por la posesión que hacían de los lugares que consideran como propios para desarrollar sus actividades, su posterior permanencia en el mismo y el actual desplazamiento que está sufriendo por la vigilancia municipal.

Al poco rato de que yo llegué, dos mujeres se dividieron el parque y cada una se quedó con la mitad. Y una de ellas nos hizo comprar un gafete que costaba 10 pesos para permitirnos vender en su lado del parque, y pasaba y revisaba que tuvieras tu gafete y decía quién sí y quién no podía vender, y si no traías el gafete te corría. Todo era traición para ellas. Pero conforme esa mafia creció y el parque se llenó de gente que literalmente ponía sus puestos en las bancas y en el piso, el ayuntamiento llegaron (sic) a quitarlas y entonces empezaron a rentar casas que hay cerca (bazares) (Ana María, entrevista personal, 2019a).

Regina tiene 32 años y comenzó a vender maquillaje chino, "pero del bueno", hace dos años en las afueras de Rectoría cuando descubrió que ganaba más siendo su propia jefa que como secretaria en un horario laboral de 8 horas y poco a poco se fue integrando al parque. Ahora ya no se encuentra dentro de él, pues ya tiene una camioneta que estaciona justo al lado sobre Instituto Literario, abre la cajuela y las clientas llegan solas. Si algún policía se acerca, basta con bajar la cajuela.

Para mí fue muy complicado empezar a vender en el parque porque no entendía nada, ni cómo se debía entablar el trato con las otras vendedoras ni las formas en que se entendían para ayudarse o de reacción $(s i c)$ frente a la policía. Cuando los policías empezaron a quitarnos porque no teníamos permiso, me tocó ver que se subieron (sic) a una chava a una patrulla y se la llevaron. Y entonces se pusieron más estrictos y tuvieron, tuvimos, que

\footnotetext{
${ }^{8}$ Cuando se refiere a "semana", quiere decir martes y viernes, que son los días de venta en el parque.
} 
alejarnos del parque, pero al poco tiempo volvimos, aunque sí es cierto, que vamos y venimos afuera de Rectoría o a un lado del Toks para que no nos vean siempre ahí o en el mismo lugar (Regina, entrevista personal, 2019).

Lucía comenzó vendiendo comida la primera vez que su esposo estuvo más de seis meses sin empleo formal. Afirma que las ventas eran muy buenas, pero el cansancio era mucho; además, en ese entonces su hija tenía ocho años y había que hacerse cargo de la casa, de la escuela, de la niña, de comprar los insumos para su negocio y un día simplemente colapsó físicamente. Ahora ella carga toda su mercancía en una mochila escolar. Para ella es mucho mejor hacerlo de esta forma porque siempre usa el autobús y con el tiempo aprendió que si hay algo que molesta mucho al ayuntamiento es que:

[...] hay quienes llegaban y ponían todo su tendido, su reguero, toda su plaza y dejaban basura, no te dejaban ni sentar en las bancas que se supone son de todos y entonces ya había policías por todo el primer cuadro del parque, y ya hasta cuando te ven con una mochila saben que vas a entregar (Lucía, entrevista personal, 2019a).

Teresa tiene 29 años y tres hijos entre los cuatro y los 10 ańos, ella aprovecha los horarios que le quedan libres después de llevar y recoger a sus hijos de la escuela para entregar su mercancía. Se casó muy joven y no pensó siquiera en estudiar. Ella también lleva una mochila, usa el transporte público y tiene que tranquilizar a sus hijos cuando sus clientas tardan más de lo acordado. Pacta las ventas por medio de Facebook. Lleva poco más de un año dedicándose a esto desde que su marido la dejó y "no respondió más por sus hijos”. Habla de su desesperación, de la necesidad que existe para que las vean a todas, para que no les prohíban vender porque "intentamos ganarnos honradamente la vida".

Somos muchas mujeres, todas somos diferentes, hay chavitas bien chavitas $(s i c)$. Yo cuando llego al parque sólo entrego lo más rápido que puedo porque parece que estoy vendiendo droga porque todo te están checando, ¿no? (Teresa, entrevista personal, 2019).

Guadalupe no revela su edad, aunque luce como una mujer de 50 años, viste muy bien porque "si las chicas ven la calidad de ropa que yo uso, pues confían en mí”. Ella tiene una carrera profesional trunca y es casada, tiene tres hijos adolescentes que están estudiando la preparatoria y la licenciatura y decidió vender cuando se dio cuenta que lo que ganaba su esposo era insuficiente. Llegó a vender al parque hace dos años porque sus conocidas la integraron, al igual que a Lucía (quienes no son amigas y sí rivalizan en 
cuanto a las clientas) a los grupos que hay en Facebook en donde tiene una página. Vio en el parque un lugar idóneo para realizar la compraventa porque descubrió que es un lugar de contacto entre mucha gente y así se daba a conocer más. Antes pasaba de dos a tres horas parada ahí, pero conforme se fue acreditando comenzó a pasar menos tiempo en ese lugar, ahora sólo permanece veinte minutos en lo que entrega y se va. Su hijo la acompaña y la espera cerca, en un automóvil que no luce viejo, ella no usa mochila, no usa el transporte público. Pero ha tenido encuentros con las autoridades municipales.

En dos ocasiones se acercaron los de Gobernación (sic) para decirme que no podía estar ahí, pero pues realmente lo único que les dije es que no estaba vendiendo mis productos y que sólo estaba entregando, y de alguna manera también les dije que no estaba causando alguna falta. Yo trato de ser muy cuidadosa, entrego muy discretamente (Guadalupe, entrevista personal, 2019a).

Dos de ellas coinciden en que al principio había a quienes les rentaban "un cachito de las bancas de piedra en 25 pesos" para poder trabajar. Una de ellas recuerda que La Morena, una de las señoras que participó en la virtual división del parque y que se adueñó ilegalmente de la mitad de él, tenía tratos con servidores públicos del ayuntamiento y les pagaban a

[...] los mismos que se supone que te tenían que ir a quitar, eran quienes les avisaban cuando los mandaban a inspeccionar, para que recogieran sus cosas y se fueran antes de que ellos llegaran. Y por eso las más 'colmilludas' (sic) te cobraban 25 pesos, 30 pesos, 50 pesos para avisarte que te tenías que quitar (Lucía, entrevista personal, 2019a).

La hija de Lucía tiene una enfermedad congénita cuyo tratamiento es muy costoso y ella encontró en la venta de ropa en el Parque "Simón Bolívar" la oportunidad de estar al pendiente de su hija, de llevarla y recogerla de la escuela, de no dejarla sola. Halló también la forma de hacer prosperar su negocio.

Lo que a mí me pagan en una quincena yo lo saco y sin estar metida tanto tiempo en un solo lugar. Yo trabajo realmente desde mi casa, porque ahí tomo mis fotos, ahí publico desde mi celular y mientras hago eso puedo lavar o cocinar... No he pensado mucho en moverme de aquí porque mis clientas ya saben en dónde estoy, incluso si no podemos comunicarnos por teléfono. Yo ya me acredité aquí, aunque me tenga que mover de vez en cuando, pero aquí mismo (Lucía, entrevista personal, 2019b).

Ana María habla de las desventajas de dedicarse al comercio informal, una de ellas es la que se vincula con el manejo de la tecnología: 
Yo no cobro con tarjeta porque no entiendo lo de las comisiones y por eso sólo cobro en efectivo. Cuando ellas (sus compradoras) no llegan, me detienen la ropa y termino malbaratándola (Ana María, entrevista personal, 2019b).

Guadalupe lo toma con la tranquilidad que su condición le da. Afirma que ciertamente al ser su propia jefa

[...] tú eres quien compra, tú eres el (sic) que entrega, tú eres el (sic) que se hace cargo de todo, pero a mí, mis hijos me ayudan, me enseńaron a usar el teléfono y el Facebook, otro me trae y me lleva a comprar y a entregar y me acompańa para no dejarme sola. Todo tu ingreso es para ti y para tu familia porque no tienes empleados (Guadalupe, entrevista personal, 2019a).

Para Guadalupe, el parque no significa nada, lo ve sólo como ese centro de reunión donde muchas mujeres intercambian o venden cosas, pero reconoce que para la mayoría de ellas es un espacio que les permite generar ingresos para mantener su hogar. Sostiene que tienen una muy buena relación con aquellas que se sitúan cerca de ella porque al verla mayor, la buscan para que las ayude cuando las molestan, sobre todo las más jóvenes. Es curiosa la manera en la que ella misma ve su actividad:

Yo soy muy respetuosa de las leyes y trato de que sí (sic), no se haga un mercado público ahí, lo único es que nos dejen hacer el intercambio de compraventa (Guadalupe, entrevista personal, 2019b).

Pero cuando se le pregunta sobre si su actividad es legal, sobre los impuestos, sobre el reglamento municipal establecido, sostiene que es una cuestión de mercado local que debe ser apoyada porque muchas familias dependen de este tipo de comercio y no están robando.

Por su parte, cuando se le pregunta qué significó el Parque "Simón Bolívar" cuando empezaba a vender, Lucía dice tras un suspiro:

Una oportunidad. Todo empieza en algún lugar y con algún acontecimiento. El mío es aquí y me ha permitido conocer a muchísimas mujeres que tienen muchísimas ganas de salir adelante, que de alguna u otra manera necesitan trabajar para llevar un ingreso a su casa, que de muchas de ellas su único ingreso es una venta aquí (Lucía, entrevista personal, 2020).

Lucía responde sobre su actividad comercial:

A lo mejor no es la manera correcta, no es este (sic) el mejor lugar para hacerlo, pero estamos en un país donde las oportunidades son muy pocas y si tú encuentras una para generar un ingreso, pues obviamente lo vas a tomar. 
Porque si lo ves a fondo hay familias que se ganan la vida de esta manera. No asaltamos, no traficamos. Te vendemos algo que te es de utilidad y es más barato que en una tienda y nos apoyas y el dinero a final de cuentas se queda aquí (Lucía, entrevista personal, 2020).

Las mujeres que se han apropiado del Parque "Simón Bolívar" de forma económica en su vertiente del comercio informal se enfrentan todos los días al engaño de los proveedores, al incumplimiento o la morosidad de los clientes que les compran, al rechazo social de quien las excluye por su condición social, a los enfrentamientos o tratos injustos con los representantes de la autoridad municipal. Entre estas mujeres existen diferencias básicas que determinan la forma en que se apropian físicamente del espacio público: no es lo mismo aquella que llega en un auto propio y no depende en sus horarios más que de los acuerdos que sostiene con sus compradoras, frente a la que carga una mochila de 20 kilos, usa el transporte público, camina largos trayectos y enfrenta las inclemencias del tiempo. Tampoco son iguales las decisiones que toma aquella mujer que cuenta con un teléfono inteligente que le permite tener acceso constante a internet y cuyo conocimiento de las plataformas sociales le ayuda a concretar las ventas, e incluso a recibir los pagos antes de la entrega de la mercancía; a ella le basta con llevar sus productos separados en bolsas con el nombre de su cliente, pararse determinado tiempo en el parque como si disfrutara el paisaje y entregar sin llamar la atención. Porque del otro lado está aquella que no sólo no posee la capacidad adquisitiva para tener un teléfono con las características necesarias para el mercadeo virtual, sino la que ni siquiera sabe usar uno más que para lo elemental, y entonces su apropiación física del espacio es distinta: ella tiene que mostrar la mercancía para que los transeúntes o los usuarios puedan verla de primera mano. Debe permanecer más tiempo para lograr una venta por la que valga la pena haber ido y es mucho más vulnerable porque su actividad es visible y resulta difícil que puedan negar la infracción a la norma establecida.

Estudiar el Parque "Simón Bolívar" como bien común a través de la apropiación económica de las mujeres permite comprender la complejidad de las dimensiones que intervienen en el uso de un espacio público, porque otros espacios, aunque coincidan en algunos rasgos esenciales, se construyen y reconfiguran en formas muy diferentes en función del uso y la apropiación que se hace de ellos.

Las formas de apropiación que los grupos hacen del espacio del parque muestran su carácter de bien común, no sólo porque existen reglas formales e informales que les permiten el acceso, uso y control de espacios físicos; sino también por las relaciones de cooperación y de conflicto que se establecen entre ellas y por los acuerdos que sustentan la posibilidad 
de que realicen tales actividades. Es pertinente notar, por ejemplo, que la apropiación de los espacios físicos, por vendedoras y compradoras, no podría darse sin la tolerancia de las autoridades que vigilan, quienes permiten que se ejerzan medidas informales de control y adscripción de bancas y lugares; lo que evidencia la existencia de acuerdos tácitos que articulan la gobernanza del parque. Una muestra de ello se concretó en mayo de 2020, con la ruptura de acuerdos cuando, con motivo de la pandemia generada por el COVID-19, las autoridades municipales cerraron al público los accesos al parque, como medida sanitaria que además se proponía evitar la concentración que genera la compraventa de productos por internet; pero las mujeres vendedoras que efectúan las entregas de mercancía permanecieron en el perímetro del parque, sin acatar las disposiciones (Ramos, 2020).

La exploración del uso del parque en su dimensión de temporalidad confirma asimismo la propuesta de Schlager y Ostrom (1992), de que la apropiación y el ejercicio de los derechos de propiedad se configuran como una combinación de derechos y no como un derecho aislado, ya que quienes se apropian del espacio pueden hacerlo en forma acumulativa y distinta para cada usuario o tipo de usuario y que las decisiones colectivas funcionan mejor si el espacio se considera un ámbito policéntrico, con posibilidades de auto-organización a través de las prácticas de los actores involucrados (Poteete et al., 2012).

A continuación, se muestra el cuadro 1 en el que se resumen los rasgos generales de los usuarios del parque.

\section{Cuadro 1}

\section{Características y perfiles de usuarios del parque}

\begin{tabular}{|c|c|c|}
\hline Caracteristicas & \multicolumn{2}{|r|}{ Especificaciones } \\
\hline \multirow{6}{*}{$\begin{array}{l}\text { Perfil promedio } \\
\text { de vendedoras } \\
\text { informales }\end{array}$} & Edad & Entre 28 y 50 ańos \\
\hline & Género & Mujer \\
\hline & Estado civil & $\begin{array}{l}60 \% \text { Casadas } \\
40 \% \text { Solteras }\end{array}$ \\
\hline & Número de hijos & $\begin{array}{l}60 \% 3 \text { hijos } \\
20 \% 2 \text { hijos } \\
20 \% 1 \text { hijo }\end{array}$ \\
\hline & Nivel de estudios & $\begin{array}{l}\text { 20\% Secundaria trunca } \\
40 \% \text { Preparatoria concluida } \\
\text { 20\% Carrera técnica } \\
20 \% \text { Licenciatura trunca }\end{array}$ \\
\hline & Productos & $\begin{array}{l}80 \% \text { Ropa de paca de segunda mano } \\
20 \% \text { Maquillaje }\end{array}$ \\
\hline
\end{tabular}


Cuadro 1 (continuación)

\begin{tabular}{|c|c|c|}
\hline Caracteristicas & & Especificaciones \\
\hline & Medio de venta & $\begin{array}{l}80 \% \text { Facebook } \\
20 \% \text { Presencial }\end{array}$ \\
\hline & Tiempo & $\begin{array}{l}20 \% 5 \text { años } \\
10 \% 3 \text { años } \\
10 \% 4 \text { años } \\
40 \% 2 \text { años } \\
20 \% 1 \text { año }\end{array}$ \\
\hline & $\begin{array}{l}\text { Otra actividad } \\
\text { económica }\end{array}$ & $\begin{array}{l}60 \% \text { No } \\
40 \% \text { Sí }\end{array}$ \\
\hline \multirow{9}{*}{$\begin{array}{l}\text { Perfil promedio } \\
\text { de compradoras }\end{array}$} & Edad & Entre 28 y 35 años \\
\hline & Género & Mujer \\
\hline & Estado civil & $\begin{array}{l}25 \% \text { Casadas } \\
75 \% \text { Solteras }\end{array}$ \\
\hline & Número de hijos & $\begin{array}{l}75 \% 1 \text { hijo } \\
25 \% \text { Sin hijos }\end{array}$ \\
\hline & Nivel de estudios & $\begin{array}{l}25 \% \text { Doctorado } \\
25 \% \text { Maestría } \\
50 \% \text { Licenciatura }\end{array}$ \\
\hline & Empleo & $100 \%$ Formales en organismos públicos \\
\hline & Productos & $\begin{array}{l}100 \% \text { Ropa de paca de segunda mano } \\
\text { De ese } 100 \% \text {, hay } 20 \% \text { de mujeres que } \\
\text { compran maquillaje además de la ropa de } \\
\text { paca. }\end{array}$ \\
\hline & Medio de compra & 100\% Facebook \\
\hline & Tiempo & $\begin{array}{l}25 \% 5 \text { años } \\
25 \% 3 \text { ańos } \\
25 \% 2 \text { años } \\
25 \% 1 \text { ańo }\end{array}$ \\
\hline \multirow{4}{*}{$\begin{array}{l}\text { Perfil promedio } \\
\text { de usuarios (activida- } \\
\text { des recreativas y de } \\
\text { ocio) }\end{array}$} & Género & $\begin{array}{l}\text { 66.6\% Hombre } \\
\text { 33.3\% Mujer }\end{array}$ \\
\hline & Uso & $100 \%$ Ocio y disfrute \\
\hline & $\begin{array}{l}\text { Solos o acompaña- } \\
\text { dos }\end{array}$ & $\begin{array}{l}100 \% \text { Acompañados (los entrevistados } \\
\text { fueron usuarios que iban acompańados) }\end{array}$ \\
\hline & Periodicidad & Lunes a viernes \\
\hline
\end{tabular}

Fuente: elaboración propia con base en las entrevistas realizadas.

Nota: No se incluyen como usuarios a los vendedores de los comercios formales que se encuentran en el contorno periférico del parque. 
Los datos permiten observar diferencias entre los grupos de mujeres vendedoras y compradoras. Las vendedoras son de más edad, menor escolaridad y, en su mayoría, tienen responsabilidades familiares, condiciones que se infiere inciden como motivaciones laborales asociadas a necesidades económicas. Las compradoras son más jóvenes, de mayor escolaridad, en mayor proporción solteras, con menor número de hijos y cuentan con un empleo formal. Los perfiles evidencian también diferencias en las formas de apropiación del espacio, sus ritmos y tiempos, entre hombres y mujeres; esas diferencias pueden ser contextualizadas en las barreras existentes para el acceso de las mujeres al empleo formal, en la desigualdad de oportunidades de educación y trabajo; así como en los patrones culturales que asignan roles y responsabilidades diferentes a las mujeres.

Se confirma entonces que los espacios públicos se reconfiguran de acuerdo con las necesidades sociales, económicas y políticas de los actores que participan de las decisiones sobre su gobernanza y que una amenaza como la pandemia que ha determinado cambios en las formas de vida de las personas en el mundo incidirá, sin duda, en la reestructuración de los espacios públicos; lo que marca aún con mayor claridad su carácter de bienes de impacto comunitario, que integran y suman acuerdos que serán incorporados a la vida cotidiana de los habitantes de las ciudades.

\section{Conclusiones}

Las interacciones en los espacios públicos difícilmente se controlan, pues están vinculadas a contextos económicos, sociales, políticos y culturales, incluso, aquellos que suelen ser imperceptibles. Todo acto relacional se manifiesta en un espacio. ${ }^{9}$ Las relaciones que tienen lugar en el espacio público son las que vinculan todos los días a las personas, aun cuando no son conscientes a cabalidad de esa participación cotidiana en la vida urbana. En este sentido, el espacio público se crea todo el tiempo y se recrea también mediante las actividades de quienes lo usan y por sus formas de apropiación.

La mirada vertida sobre los espacios públicos como bienes comunes permite verlos como ámbitos socio-territoriales y como construcciones sociales, susceptibles de ser apropiados, y comunalizados en la medida que las decisiones sobre su uso y gobernanza son compartidas. ${ }^{10}$ El locus

9 Los medios tecnológicos confieren al espacio público una extensión virtual invisible, que trasciende las dimensiones territoriales y temporales.

${ }^{10}$ La mirada sigue la tesis de Monnet sobre un sistema socio-territorial que considera el territorio como el espacio donde se realiza la acción humana, la territorialidad representa los valores que los actores atribuyen a un territorio y la territorialización, las intervenciones que se realizan sobre ese espacio (Monnet, 2010). 
del espacio público se constituye por los grupos sociales que de él participan, de la conformación de sus servicios, de las decisiones políticas, del tipo de convivencia muchas veces efímera, del comportamiento económico. La aparente fragilidad del equilibrio que sostiene a los espacios públicos resiste los embates del tiempo y el caos urbano en la medida en que existen acuerdos sobre su uso y preservación e importancia para la vida cotidiana.

En ese contexto resulta importante aceptar que existen múltiples vías en la forma de gestionar los espacios públicos que tomen en cuenta aquellos grupos que son poco visibles, marginados o las minorías, entre las que es posible incluir las formas del trabajo y autoempleo de las mujeres, el cual debe ser tratado como una reivindicación política y un asunto de interés público. Muchas de estas mujeres pelean todos los días por producir ingresos que les ayuden a sobrellevar la irremediable angustia económica.

En un país como México, cuya precarización, polarización y desigualdad económica se han agravado con el paso de los años, las estructuras y el funcionamiento de las familias han cambiado, insertos en los procesos económicos mundiales y regionales que han acompañado la globalización y la urbanización de los territorios, marcando desajustes e inestabilidades entre las personas y en los tipos de trabajo. Muchas mujeres toman las calles y ocupan los espacios públicos, realizan actividades comerciales al margen de la legalidad porque las oportunidades laborales para ellas escasean, porque sus condiciones educativas no les garantizan un salario digno, porque no tienen redes familiares que les ayuden con el cuidado de sus hijos.

\section{Fuentes consultadas}

Almada, Héctor (2014), "La apropiación del espacio público a través de las prácticas deportivas juveniles”, tesis de doctorado, El Colegio de la Frontera Norte, Tijuana.

Amin, Ash (2009), "Collective cultura and urban public space", Public Space, 2 june 2009, Barcelona, CCCB (Centre de Cultura Contemporània de Barcelona), <https://bit.ly/3fRMkn9>, 20 de octubre de 2020.

Atutxa, Ekhi (2017), "Las instituciones del común”, Viento Sur, 25 (150), Madrid, Sylone, pp. 99-105. 
Campos Cortés, Georgina Isabel y Brenna Becerril, Jorge Eduardo (2015), "Repensando el espacio público social como un bien común urbano", Argumentos. Estudios Críticos de la Sociedad, 28 (77), Ciudad de México, Universidad Autónoma MetropolitanaUnidad Xochimilco, pp. 157-176.

Carrión, Fernando (2016), "El espacio público es una relación, no un espacio", en Patricia Ramírez Kuri (coord.), La reinvención del espacio público en la ciudad fragmentada, Ciudad de México, UNAM, Instituto de Investigaciones Sociales, Programa de Maestría y Doctorado en Urbanismo, pp. 13-47.

Castro Coma, Mauro y Martí Costa, Marc (2016), “Comunes urbanos: de la gestión colectiva al derecho a la ciudad”, EURE. Revista Latinoamericana de Estudios Urbanos Regionales, 42 (125), Santiago de Chile, Pontificia Universidad Católica de Chile, Facultad de Arquitectura, Diseño y Estudios Urbanos, Instituto de Estudios Urbanos y Territoriales, pp. 131-153.

De Magalhães, Claudio (2010), "Public Space and the Contracting-out of Publicness: A Framework for Analysis", Journal of Urban Design, 15 (4), London, Taylor \& Francis, pp. 559574, doi: 10.1080/13574809.2010.502347

Fonseca Rodríguez, Jessica Montserrat (2015), "La importancia y la apropiación de los espacios públicos en las ciudades", Paakat. Revista de tecnología y sociedad, 4 (7), Jalisco, Universidad de Guadalajara, <https://bit.ly/2VgM5sB>, 7 de febrero de 2020.

Gaceta Municipal Especial (2019), "Bando Municipal de Toluca”, 5 de febrero, Toluca, Honorable Ayuntamiento Municipal de Toluca, <https://bit.ly/33rX3Qb>, 11 de noviembre de 2019.

Giglia, Ángela (2013), "Entre el bien común y la ciudad insular: la renovación urbana en la Ciudad de México", Alteridades, 23 (46), Ciudad de México, Universidad Autónoma MetropolitanaUnidad Iztapalapa, pp. 27-38.

Lefebvre, Henri (2013), La producción del espacio, Madrid, Capitán Swing.

Martínez Valdés, Valentina; Silva Rivera, Evodia y González Gaudiano, Edgar (2020), "Parques urbanos: un enfoque para su estudio como 
espacio público", Intersticios Sociales, 10 (19), Jalisco, El Colegio de Jalisco, A.C., pp. 67-86.

Merino Pérez, Leticia (2019), "Introducción al estudio de los bienes comunes", Ciudad de México, UNAM, <https://bit.ly/3lp4KwE>, 19 de mayo de 2019.

Merino Pérez, Leticia (2014), "Perspectivas sobre la gobernanza de los bienes y la ciudadanía en la obra de Elinor Ostrom", Revista Mexicana de Sociología, 76 (Número Especial dedicado a Elinor Ostrom), Ciudad de México, UNAM, Instituto de Investigaciones Sociales, pp. 77-104.

Monnet, Jerôme (2010), "Le territoire réticulaire", Revista Anthropos: Huellas del conocimiento, núm. 227, Barcelona, Proyecto A Ediciones, pp. 91-104.

Ostrom, Elinor (2014), "Más allá de los mercados y los Estados: gobernanza policéntrica de sistemas económicos complejos", Revista Mexicana de Sociología, 76 (Número Especial dedicado a Elinor Ostrom), Ciudad de México, UNAM, Instituto de Investigaciones Sociales, pp. 15-70.

Ostrom, Elinor (2011), El gobierno de los bienes comunes. La evolución de las instituciones de acción colectiva, Ciudad de México, Fondo de Cultura Económica/UNAM, Centro Regional de Investigaciones Multidisciplinarias, Instituto de Investigaciones Sociales.

Peñaloza García, Inocente (2015), La Universidad y su entorno. Recuento (crónicas, artículos y reseñas), Toluca, Secretaría de Educación del Gobierno del Estado de México, Fondo Editorial Estado de México, Consejo Editorial de la Administración Pública Estatal.

Porras, Francisco (2016), Gobernanza: propuestas, limites y perspectivas, Ciudad de México, Instituto Mora.

Poteete, Amy; Janssen, Marco y Ostrom, Elinor (2012), Trabajar Juntos: Acción colectiva, bienes comunes y múltiples métodos en la práctica. Ciudad de México, UNAM/IASC/CIDE/Colsan/CONABIO/ CCMSS/FCE/UAM.

Ramos, Filiberto (2020), “Cierran parque Simón Bolívar por Covid-19 y vendedores por internet”, El Sol de Toluca, 12 de mayo, Toluca, 
Organización Editorial Mexicana, Local, <https://bit.ly/37k4x9f>, 12 de mayo de 2020.

Schlager, Edella and Ostrom, Elinor (1992), "Property-Rights Regimes and Natural Resources: A Conceptual Analysis", Land Economics, 68 (3), Madison, University of Wisconsin Press, pp. 249-262, doi: $10.2307 / 3146375$

Segovia, Olga (2007), "Presentación”, en Olga Segovia (edit.), Espacios Públicos y Construcción Social. Hacia un ejercicio de ciudadanía, Santiago de Chile, Ediciones SUR, pp. 9-11.

Subirats, Joan (2016), "Explorar el espacio público como bien común. Debates conceptuales y de gobierno en la ciudad fragmentada", en Patricia Ramírez Kuri (coord.), La reinvención del espacio público en la ciudad fragmentada, Ciudad de México, UNAM, Instituto de Investigaciones Sociales, pp. 73-98.

Torres Veytia, Eduardo (2009), "Elucubrando la identidad en el Espacio Público", Ciudad de México, Researchgate, <https://bit. ly/37mjGXB>, 14 de octubre de 2019.

Vázquez Ceballos, Cristo Avimael; Medrano González, Ramiro; Tapia Quevedo, Jorge y San Martín Barrios, Pedro (2011), "Espacio público e informalidad: el caso del programa de apoyo para la reubicación del comercio popular en la ciudad de México", Antropología Experimental, núm. 11, Andalucía, Universidad de Jaén, pp. 139-158, <https://bit.ly/3qcKrq1>, 19 de noviembre de 2019.

Vergara Vidal, Jorge (2012), "Bienes comunes urbanos. Una aproximación inicial”, Diseño Urbano y Paisaje, 9 (23), Santiago de Chile, Universidad Central de Chile, Facultad de Arquitectura, Urbanismo y Paisaje, Centro de Estudios Arquitectónicos, Urbanísticos y del Paisaje, pp. 37-51, <https://bit.ly/36nRrIX>, 29 de octubre de 2019.

\section{Entrevistas}

Ana María, "Entrevista personal”, (2019a), por el autor, presencial, Parque "Simón Bolívar", 9 de julio de 2019.

Ana María, "Entrevista personal”, (2019b), por el autor, presencial, Parque "Simón Bolívar", 2 de agosto de 2019. 
Guadalupe (2019a), "Entrevista personal", por el autor, presencial, Parque "Simón Bolívar", 24 de septiembre de 2019.

Guadalupe (2019b), "Entrevista personal", por el autor, presencial, Parque "Simón Bolívar", 8 de octubre de 2019.

Lucía (2019a), "Entrevista personal”, por el autor, presencial, Parque "Simón Bolívar", 5 de julio de 2019.

Lucía (2019b), "Entrevista personal”, por el autor, presencial, Parque "Simón Bolívar", 27 de septiembre de 2019.

Lucía (2020), “Entrevista personal”, por el autor, presencial, Parque "Simón Bolívar", 14 de enero de 2020.

Regina (2019), "Entrevista personal”, por el autor, presencial, Parque "Simón Bolívar", 20 de agosto de 2019.

Teresa, (2019), "Entrevista personal”, por el autor, presencial, Parque "Simón Bolívar", 8 de noviembre de 2019.

Recibido: 12 de junio de 2020. Reenviado: 8 de octubre de 2020. Aceptado: 6 de noviembre de 2020.

Gloria Jovita Guadarrama Sánchez. Doctora en Ciencias Políticas y Sociales por la Universidad Nacional Autónoma de México y miembro del Sistema Nacional de Investigadores, nivel II. Actualmente se desempeña como docente investigadora en El Colegio Mexiquense, A.C. Sus líneas de investigación son: instituciones, políticas públicas, género, asistencia social, sociedad civil y tercer sector. Entre sus más recientes publicaciones se encuentran, como autora: "El modelo de fundaciones comunitarias en México", Cooperativismo \& Desarrollo, 27 (115), Bogotá, Universidad Cooperativa de Colombia, pp. 1-27 (2019); como coautora: "Gobernanza y derecho al agua: Prácticas comunes y particularidades de los comités comunitarios de agua potable”, Sociedad y Ambiente, 20 (2019), San Cristóbal de Las Casas, El Colegio de la Frontera Sur, pp. 53-77 (2019); como co-coordinadora: ¿Problemas complejos, soluciones nuevas? Debates sobre el desarrollo social sustentable en el Estado de México, Zinacantepec, El Colegio Mexiquense, A.C. (2019).

Pamela Monserrat Pichardo Martínez. Maestra en Comunicación Estratégica para Gobiernos e Instituciones por el Instituto Universitario 
de Investigación Ortega y Gasset y maestra en Estudios Sustentables Regionales y Metropolitanos con énfasis en Economía Regional por la Universidad Autónoma del Estado de México. Actualmente estudia el doctorado en Ciencias Sociales en El Colegio Mexiquense, A.C. y es docente en la Facultad de Ciencias Políticas y Sociales en la Universidad Autónoma del Estado de México. Sus líneas de investigación son: teoría política y democracia en Latinoamérica, así como filosofía de la ciencia y epistemología. 